\title{
Neuromanagement - the Impact of Neuroscience on the Organizational Performance
}

\author{
Alina Mirela Teacu (Parincu) \\ teacualina@yahoo.com \\ Dunarea de Jos University of Galati, Romania
}

\begin{abstract}
The purpose of this paper is to overview the linkage between the full of perspectives field of neuroscience with individual and organizational performance. I gave an overview of neuromanagement, from neuroscience, basic functioning of the brain, human basic needs, application in the workplace and the impact on overall performance. The worldwide necessity is to continuously improve the human and organizational performance, in order to thrive in this challenging and turbulent arena of business environment. The findings reveal that neuromanagement, as a field derived from neuroscience, has direct impact towards performance and opens avenues for future researches, which can positively and strongly impact the individual performance and global performance of an organization.
\end{abstract}

Keywords: Neuromanagement, neuroscience, brain activity, emotions, human performance, organizational performance.

\section{Introduction}

The arena of human and organizational performance is extremely challenging and demanding due to the fact that there is an acute need to continuously find new ways of improving performance in order to thrive in the competitive entrepreneurial system, since superior performance is paramount to business success [1].

The main objective of this article is to overview the linkage between the promising and full of perspectives and opportunities field of neuroscience with human and organizational performance, through the lens of neuromanagement approach.

The latest innovation in management and leadership of individuals and organizations is linked to the applied neurosciences into the business, which is the ultimate gateway to a new world full of challenges and opportunities [2].

In this dynamic and competitive business environment, the triumph of an organization is strongly related to higher performance, which to a large extent, depends on having high quality leadership and individuals, which is vital to gaining a competitive differentiator in order to maximize the global organizational performance [3].

\section{Framework of neuroscience}

The brain research is enormous and the latest years' technological revolution allowed neuroscience to blossom.

The neuroscience context is rich and broad, being a multidisciplinary field that combines complex fields of study such as anatomy, physiology, molecular biology, cytology, developmental and molecular biology, mathematical modeling and psychology to comprehend the fundamental and emergent properties of neurons and neural circuits [4].

The neuroscience represents the scientific study of the nervous system in general and the brain, specifically and covers a large spectrum of disciplines that are functioning in parallel and are overlapping due to the enormous complexity of the human brain that hosts cognitive, biological and chemical processes [5].

The formal disciplines in the neuroscience are: neurology - part of human medicine, that deals with disorders of the nervous system; neurobiology - the study of the structure, function 
and development of nerve cells and the nervous system; neurochemistry - the study of the chemical processes at a cellular level in the nervous system; neurophysiology - a sub-discipline of physiology which studies the performance and reaction of our nervous system to external stimuli; neuropsychology - the study of behavior in combination with neuroscientific technologies; neuropsychotherapy - which uses neuroscientific insights to treat psychological disorders, considering the fact that brain forms its view of the world through structural communication and that dysfunction in personality can also be represented by dysfunctions in the biology of the brain; cognitive Neuroscience - which deals with the neural substrates of cognition, mental processes, being effective in mapping the brain and all of its regions based on its cognitive functions.

The neurosciences are comprehensive and interdisciplinary, studying the functioning of the nervous system as a whole, with approaches that target both, molecular level and also the human behavioral level, using the techniques and methodologies developed by the scientists and researchers, together with the advances of technology in brain imaging.

The main actor in the neuroscience is the brain, as the central processing element of human beings, which defines who we are, housing the memory, consciousness, and our sense of "self" on top of our cognitive interaction with the entire world [5].

The brain consists of around 100 billion neurons and is a massive network of connections with more than 100 trillion connections between each other, in different regions. The left hemisphere of the brain shelters the facts and details, the specifics of language, vocabulary and grammar and the right hemisphere has broader connections to empathy, emotions, and most importantly to the holistic and big picture view of the world [5].

Everything that we do, action, decision, is governed by emotions. In order to understand the emotion, we must understand how our brain works. According to Paul MacLean three layer model, the human brain, in its evolved stage, can be divided in three different regions: the reptilian brain or the brain stem, the limbic, emotional brain and the neocortex [6].

The reptilian brain, the oldest part of the brain, in an evolutionary sense and plays a critical role in human survival. It regulates the basic life functions such as breathing, heartbeat, basic reflex and movements.

The limbic system, or the emotional brain, called also the inner cortex, is our emotional center, housing human values, beliefs and attitudes and processes a large spectrum of emotions. The structure of the limbic system includes the amygdala - the emotional processing units, the hippocampus - the memory center of the brain, the cingulate cortex -which matches and balances the information in the limbic system and the nucleus accumbens - the brain's reward centre [7].

The cerebral cortex or the logical brain is the youngest part of the brain. The thinking brain is the one that differentiates us most from other animals and other life forms, and it is sheltering higher forms of information processing. [6]

The three parts of the brain are constantly interconnected and process information in parallel.

The evolution of cognitive neuroscience and technology of brain imaging opened the gateways to interface directly with activity in the brain and allowed the discovering of important insights of the brain that impacts the human behavior.

In the context of neuromanagement and the applicability to the business environment, from the plethora of information related to brain functioning, there are some relevant insights: plasticity of the brain which is the ability of the brain to grow, rewire and reform its connections and functions, being the heart of learning and memory and the one that drives the developing brain and the learning processes of humans. Another important insight of the brain is that emotions play a decisive role in the change processes of the brain and by stimulating the reward center in the brain we can activate processes that will enhance learning, habit formation and positive emotions in the brain [8]. Thirdly, the mirror neurons, which have the ability to mirroring others actions and that show that we are connected to the world and people around us 
and we live related partially with the actions, emotions and intentions that we perceive from others [9]. The mirror neurons are crucial in many learning process but most important in the reading of emotions and empathy, and can activate to actions, emotions and also intentions.

Due to technological evolution and the latest techniques of brain imaging, scientists and researchers draw some important conclusions after measuring different regions of the brain: the limbic system, the emotional part of brain, turned out to be more active than the logical brain, with more than 6 billion nerve cells that are sending messages in any second to our thinking one, compared to 100 neuronal stimulations in the logical brain. The thinking brain does not become consciously aware of the emotions our emotional brain is sending every second [10]. The emotions are operated unconsciously, which facilitates us behaving without paying attention to the emotion that we really feel or the attitude it is connected to [11].

Neuroscience is the advance study of human's brain and mental processes. The evolution of neuroscience helped the scientists to identify the relationship between management, economic, leadership and organizational behavior.

Neuromanagement is a part of neurosciences which study the brain activity involved in the management processes of an organization, decision making perception [12] and it deals with the management and understanding of brain towards emotions, thoughts and behaviors [13].

\section{Neuromanagement and organizational performance The linkage}

The neuroscientific research brought into the light important findings that reshaped the concept of human being' motives and drives and also questioned the concepts of consciousness, choice, morality and free will. This is a very important aspect, because business and organizational psychology have focus on the type of person interacting with, employee, leader or consumer. The concept of man is the one that had driven the evolution of economic theory over time. Historically we can distinguish four stages of perception of man, and surely, we entered the fifth stage - the one of the "brain-directed man".

The view of man has evolved from its first stage, the homo economicus or economic man phase, when Smith stated that man acted "regard to their own interest" [14] and soundly grounded by Taylor [15] who aimed, with his researches and application of science, to support organizations reach higher performance through systemic use of employees to increase productivity, using scientifically proven methods and besides this, to improve the quality of employees' life through higher pay, due to increased productivity. This theory, based on the viewpoint that the only interest of man was based on economic advantage and the man could be motivated by financial means only. This theory had great influence and shaped the management thinking for almost a century.

The social man or homo sociologicus stage was the second phase in concept of man development and was the counterpoint of scientific management. Mayo' Hawthorne studies [16] were the ones that initiated the human relations movement which brought the employee to the forefront [17]. In this stage, the employee was perceived as a social being and it was strengthened the importance of interpersonal relations for the workplace, with implicit strong impact on workplace performance, through increased motivation and productivity determined by internal drive and the need of employee satisfaction.

The third stage was the self-actualising man which center the man that aim to accomplish higher needs and pursue its own self-development. This phase was strongly driven by Maslow's work that stated that in order to reach the self-actualisation level you need to go through the four lower levels of the pyramid which represent the deficit needs that must be fulfilled in a certain order, such as physiological needs - as food, drink, shelter, safety needs - as law and order, security of job and resources, belonging needs within family and friends and esteem needs - as self esteem, achievement and respect by others. The self actualising is the higher sphere of needs and represent areas such as morality, creativity, problem solving, and lack of prejudice [18].

Despite the previous limited views of man, one dimensional or with single motivational 
drives such as man driven by money, social needs or specific needs that gave organizations limited dimensions of work and performance in the working place.

The complex man phase looked at all views of man, in a holistic manner, with all its complexity - "the nature of human nature" [19]. The complex man concept is based on a series of assumptions such as the different motives that can change depending on certain conditions according to different personal situations and the level of development; the capability of employees to learn from organizational experience and to implement this to new situations; the different reaction of employees to various management strategies and motives. The nature of human nature is therefore the complex man, an ever changing man that will change behavior according to different situations and environments. Man can change its motivations depending on external circumstances and are driven by multiple motivations [20].

This complexity of man has given rise to numerous challenges in organizational development and performance. The current phase of man concept is called the brain directed man stage. Latest research in neuroscience allows deep and concrete understanding of human behavior. Based on the brain science insights, human being can be observed how their brain functions and how they are operating, with impact on their behavior and motives. Neuroscience allows us to draw powerful conclusions to human behavior.

The brain research is enormous and the insights are providing concrete understandings of human behaviors, which are very interesting and fruitful for organizations and their leaders, employees.

Researches have revealed that human behavior derives from the brain and different regions of the brain influence certain types of behavior, which is not based on rationality but on different motives that stem from the interaction of these brain regions. Moreover, different patterns and triggers are deeply programmed based on the multitude of experiences developing from birth on. Another important neuroscience insight is that emotions are affective drivers for behavior and to a greater or lesser extent these emotions are present in most cognitive processes.

The neuroscientific research knew a spectacular development in the last decade and so many fields have been derived from this. The scientific research related to neuronal bases of human interactions in the economy, in a holistic manner, form the broader concept of neuroeconomics.

Neuromanagement is one of the domains with a sustainable body of research that looks into the brain processes that are driving the management processes in an organization, from a personal to a personnel level and helps define the underlying processes defining the success of various methods, tools and processes. Through this discipline, we can understand how the human brain is acting, reacting and interacting in different business context with the application of methods and knowledge from neuroscience. [5].

Neuromanagement is exploring human brain and mental processes of the people that are facing economic and management conditions, using cognitive neuroscience and brain imaging technology to analyze economic, managerial and behavioral situations and also provides relevant insights into human decision-making and social behavior in general [21].

Neuromanagement is designed to connect with the emotional brains, to build social connections, trust and link to natural human motivators, with its principles based on neurochemical and neurobiological science. Neuromanagement insights are the ones that can help organizations to manage in a proper manner the way that emotions at the workplace can influence the business outcomes and ultimately, the holistic performance.

The development within neuroscience opened up new gateways to leadership development and organizational performance and the brain research brought a new light on how the brain functions in real time situations of management or leadership.

Improving the quality of leadership, of the relations between the leaders and employees, represents an important part of business strategies for most of the organizations. Studies conducted over time showed that the best leaders are the ones that have both, strong business skills and interpersonal skills. For the business executives with hard skills it seemed difficult to 
build soft skills therefore a new language, based on hard data of brain research, with explanations of theoretical foundations of soft skills, had to be revealed [22].

In this challenging environment and in the context of limited resources, it is important to know how the brain works when managers and employees are facing different situations, in order to become more efficient in self and others management and to be able to perform at best potential and gain the highest impact towards performance.

The necessity for more effective practices in the workplace spans many fields of activity and represents one the main concern for organizational and performance theorists. The use of social sciences to explore how humans behave within organizations proved to be limited, therefore the interest in understanding how the human brain works gain a lot of interest in order to understand human performance and its management through new insights emanating from the field of neuroscience [23].

Neuromanagement reveals a new approach of leadership and performance, individual or organizational and brings to light new manners to improve communication, leadership and productivity through the lens of mental processes and brain activity [24].

The main objective of the neuromanagement approach related to performance is to optimize the functioning of the brain and mental processes in a proper way in order to work faster, with reduced risk of errors, and to avoid that improper handling of emotions to affect the executive functions of the brain. It aims to discover the competencies directly linked to leadership development, which are decisive aspects to meet the increasingly complex need of an organization in the business environment. Neuromanagement reveals the understanding of management and leadership processes within organizations, and the reasons behind human's decision making process, bringing to light new ways to improve performance.

The variations of human behavior involved in workplace are an endless ocean of subtle differences, directly related to the evolution of human functions and the basic needs of human. The optimal condition for the development of human are strongly related to the four basic needs that are the need for attachment, the need for orientation and control, the need for self-esteem, its protection and development, the need for pleasure and avoidance of pain [25]. All of these needs are related to each other and the satisfaction of one need, will influence the others and in the end will impact human behavior in the context of performance.

The neuroscience perspective, applied on management and leadership has as primer goal the identification of biological basis for human behavior and the way it is translated into the performance of leaders and the impact of leaders on the performance of others. Therefore, neuroscience aims to explain leadership behavior and human performance. The equation of performance can be described as the sum of capability and capacity of individuals, where capability is defined by skills and behavioral competencies that addresses the capacity defined by the ability to process, store and integrate the capabilities and apply them effectively to the workplace, in order to maximize performance and achieve its greatest potential. When referring to performance, capability and capacity, this is valid to all levels, from individuals, teams to management. The combination of developing both capability and capacity is the next level of performance development, therefore the absence of any component meaning that the equation cannot be solved. Highly developed leadership and professional evolution should address both, capability and capacity, which are the elements that contribute to fostering high performance at the workplace [23].

\section{Concluding remarks}

The universal need of business environment is to continuously improve the human and organizational performance, in order to thrive in this challenging and dynamic arena of business ecosystem. There is an intensive on-going process of searching alternative ways for performance and leadership development in order to become much more effective and efficient in terms of business results.

This article aims to understand human performance and its management by organizations 
through new insights emanating from the field of neuroscience.

To be aware, in the proper way, of the scientific basis of human behavior and brain activity involved in managerial, leadership and behavioral cases in the workplace, it can provide the premises for a powerful impact towards optimal performance of individuals and organizations. To be more effective in making decisions, to know how to choose the best alternative without making mistakes, to make your employees realize their full potential, to implement more efficient change processes, to better communicate with individuals and generate the commitment of people, represent only a part of the contribution of neuroscience applied to management and leadership.

In the context of neuromanagement, it is the role of the leader to understand the needs, the behavior and the individual processes of their employees, from the brain perspective. As long as an organization has people that are performing work, the emotions are present and they will impact the business outcomes for better or for worse.

It is of crucial importance to understand the human beings and their ability to be motivated in the workplace, to determine them to be engaged and to perform at their best potential in order to strongly impact the individual and organizational performance.

The new horizons discovered by the explorers of management and leadership are related to the infinite potential of the brain and the neurocircuits that feed all the decisions.

Neuroscience ensure the scientific exactness of brain research, in order to bring out the newest insights that can be applied in management and leadership. Neuromanagement is an authentic challenge that brings new optics to the business world, revealing that new competences to triumph are not outside but inside of individuals. The findings reveal that neuromanagement has direct impact towards performance and opens avenues for future researches, which can positively impact the individual and global performance of organizations, in order to lead them to the desired future.

\section{References}

1. Neale, S., Spencer-Arnell, L., \& Wilson, L. (2011). Emotional intelligence coaching: Improving performance for leaders, coaches and the individual. Kogan Page Publishers.

2. Braidot, Néstor Pedro Neuromanagement : cómo utilizar a pleno el cerebro en la conducción de organizaciones (2008) - Ed. Buenos Aires: Granica.

3. Naila Kublmann, Chelsie A. Kadgien (2018), Neuroleadership: Themes and limitations of an emerging interdisciplinary field (2018), Healthcare Management Forum, Vol. 31(3) 103-107 ${ }^{a} 2018$.

4. Kandel, Eric R. (2012). Principles of Neural Science, Fifth Edition. McGraw-Hill Education. pp. I. Overall perspective. ISBN 978-0071390118.

5. Ghadiri, A., Habermacher, A., \& Peters, T. (2013). Neuroleadership: A journey through the brain for business leaders. Springer Science \& Business Media.

6. MacLean, Paul D (1990), The Triune Brain in Evolution. Role in Paleocerebral Functions. Plenum, New York, 1990. xxiv, 672 pp.

7. Wise, $\mathrm{R}$. A. (2002). Brain reward circuitry. Neuron, 36, 229-240.

8. Nakatani, Y., et al. (2009). Why the carrot is more effective than the stick: different dynamics of punishment memory and reward memory and its possible biological basis. Neurobiology of Learning and Memory, 92(3), 370-380.

9. Rizzolatti, G., \& Fabbri-Destro, M. (2010). Mirror neuron mechanism. In G. F. Koob, M. L. Moal, \& R. F. Thompson (Eds.), Encyclopedia of behavioral neuroscience (pp. 240-249). Burlington: Academic.

10. Tan, D., \& Nijholt, A. (2010). Brain-computer interfaces and buman-computer interaction. In BrainComputer Interfaces (pp. 3-19). Springer, London.

11. Newman, D. A., Joseph, D. L., \& MacCann, C. (2010). Emotional intelligence and job performance: The importance of emotion regulation and emotional labor context. Industrial and Organizational Psychology, 3(2), 159-164. 
12. Satpathy, J. (2012). Issues in Neuro-Management Decision Making. Opinion: International Journal of Business Management, 2(2).

13. Yousaf, Hummaira Qudsia, Rehman, Chaudhary Abdul (2017), How Neuroscience Effects on Decision Making and Leadership, International Review of Management and Business Research, Vol.6 Issue 1

14. Smith, A. (1904). An inquiry into the nature and causes of the wealth of nations (5th ed.). London: Methuen \& Co., Ltd.. Available at: http:/ / www.econlib.org/library/Smith/smWNCover.html.

15. Taylor, F. W, (1911). Principles of Scientific Management. New York: Harper \& Brothers.

16. Mayo, E. (1949). Hawthorne and the western electric company. In D. S. Pugh (Ed.), Organization theory selected readings. London: Penguin Books.

17. Bruce, K. (2006). Henry S. Dennison, Elton Mayo, and Human Relations historiography. Management and Organizational History, 1(2), 177-199.

18. Maslow, A. H. (1943). A theory of human motivation. Psychological Review, 50(4), 1-21.

19. Schein, E. H. (1980). Organizational psychology (3rd ed.). Eaglewood Cliffs: Prentice-Hall.

20. Lieberman, S. (1956). The effects of changes in roles on the attitudes of role occupants. Human Relations, 9(4), 385-402.

21. Q. Ma, X. Wang (2006), Cognitive neuroscience, Neuroeconomics, and Neuromanagement, Management World 10, 139-149.

22. Rock, David (2010), Impacting Leadership with Neuroscience, People and Strategy, suppl. Special Issue: Leading in a Time of Uncertainty; New York, Vol. 33, Iss. 4, 6-7.

23. Vorbauser-Smith, Sylvia (2010), The Neuroscience of Performance. People at their best, PageUp.

24. Du Plessis, A.J., Badenhorst, C. (2016). Managing th impact of Neuroleadership during organizational change, Under New Management: Innovating for sustainable and just futures, 30 $0^{\text {th }}$ ANZAM 2016 (Ed)(pp.1-12).

25. Grawe, K. (2006). Neuropsychotherapy: How the neurosciences inform effective psychotherapy. Mabwah: Lawrence Erlbaum Associates 